\title{
SOSYAL MEDYA BAĞIMLILIĞI İLE AKADEMİK ERTELEME DAVRANIŞI ARASINDAKİ İLISSKIIDE SOSYAL MEDYA KULLANIM AMAÇLARININ ROLÜ: BİR YAPISAL EŞİTLİK MODELİ ÇALIŞMASI
}

Emre YAKUT $^{1}$

Özlem KURU 2

$\ddot{O Z Z}$

\section{Anahtar Kelimeler:}

Sosyal Medya Kullanım Amaçları

Sosyal Medya Bă̆̆ımlılı̆̆ı

Akademik Erteleme

Yapısal Eşitlik Modellemesi

JEL Kodlarn:

C30,

C39,

I20

\author{
Received Date (Başvuru Tarihi): \\ $14 / 05 / 2020$ \\ Accepted Date (Kabul Tarihi): \\ $11 / 06 / 2020$ \\ Published Date (Yayın Tarihi): \\ $25 / 06 / 2020$
}

Günümüzde temelde bireysel teknoloji kullanımında mobile dönüş eğilimi ve internete erişimin kolaylaşması sebebiyle sosyal medyanın kullanım oranları giderek artmaktadır. Sosyal medya platformlarının çeşitliliği ve her birinin en az bir konuda günlük hayatta kolaylık sağlaması bireylerin bu platformlarda geçirdikleri süreyi artırmaktadır. Gün içerisinde sosyal medyaya ayrılan sürenin artması tıpkı diğer bă̆ımlılık türlerinde olduğu gibi bireylerin sorumlulukların yerine getirmelerinde aksamalara yol açmaktadır. Bu nedenle literatürde sosyal medya bağımlılı̆̆ı ve kullanım alanlar ile ilgili çok sayıda çalışmaya ulaşmak mümkündür. Benzer şekilde erteleme davranışı da birçok yönden incelenmekte olan bir konudur. Bu çalışma, öğrencilerin sosyal medya alışkanlıklarını kullanım amaçları ve bağımlılıkları üzerinden inceleyerek akademik erteleme davranışlarına olan etkilerine yoğunlaşmıştır. Çalışmada 399 üniversite öğrencisinden anket verisi toplanmıştır. Literatür desteği ile kurulmuş olan modeldeki yapıların geçerlik ve güvenirlik analizleri ve kurulan hipotezlerin testleri SmartPLS 3.2.9 yazılımı kullanılarak gerçekleştirilmiştir. Elde edilen bulgularla modelin bağımsız değişkeni olan sosyal medya bă̆ımlılı̆̆ının modelin aracı değişkeni olan sosyal medya kullanım amaçları ile ilişkisinin, aracı değişkenin modelin bağımlı değişkeni olan akademik erteleme davranışı ile olan ilişkisinin anlamlı olduğu ortaya konmuştur. Ayrıca bağımsız değişken ile bă̆ımlı değişken arasındaki doğrudan ilişkinin anlaml olmamasına karşın bu ilişkide sosyal medya kullanım amaçlarn değiş̧keninin tam aracılık etkisi tespit edilmiştir.
Keywords:
Social Media Usage Academic Procrastination Social Media Addiction Purposes
Structural Equation Modeling
JEL Codes:
C30
C39
$I 20$

\footnotetext{
${ }^{1}$ Dr. Öğr. Üyesi, Osmaniye Korkut Ata Üniversitesi, emreyakut@osmaniye.edu.tr

2 Arş. Gör., Osmaniye Korkut Ata Üniversitesi, ozlemkuru@osmaniye.edu.tr,
} 


\section{EXTENDED ABSTRACT}

\section{THE ROLE OF SOCIAL MEDIA USAGE PURPOSES IN THE RELATIONSHIP BETWEEN SOCIAL MEDIA ADDICTION AND ACADEMIC PROCRASTINATION BEHAVIOR: A STRUCTURAL EQUATION MODEL STUDY}

\section{LITERATURE}

\subsection{RESEARCH SUBJECT}

Internet usage of the individuals is mostly related to social media (Hootsuite \& We Are Social, 2020). People use the social media usage to get news, communicate, access to information, and for free-time activity and research purposes (Çömlekçi and Başol, 2019; Acun et al., 2017; Akıncı Vural and Bat, 2010; Taşçı and Ekiz, 2018). The reason for the spread of social media usage in daily life can be the diversity of social media usage purposes.

The concept of addiction for social media, which has an increasing number of users and hours of use, has become a popular topic in the literature. Social media addiction has similar findings to substance addiction. These findings include delaying jobs and not fulfilling responsibilities due to social media usage (Ayeni, 2019; Hootsuite \& We Are Social, 2020). This may occur as academic procrastination among students. Therefore, this study focused on a measurement model that was developed with the literature to test the effects of the addiction and usage of social media which is thought to affect students' academic procrastination behaviors.

\subsection{RESEARCH PURPOSE AND IMPORTANCE}

The study aimed to reveal the effect of social media addiction and social media usage purposes on academic procrastination behaviors. Academic procrastination behaviors have negative effects on academic achievement (Balkis et al., 2006). Testing the presented measurement tool is important to enlighten some parts of the reasons for the students' academic procrastination behaviors.

\subsection{CONTRIBUTION of the ARTICLE to the LITERATURE}

The study contributes to the literature with the enlightenment of the reasons for academic procrastination and the diversity of the application area of the structural equation model.

\section{DESIGN AND METHOD}

\subsection{RESEARCH TYPE}

This quantitative study examined the correlations between the variables and included the statistical analyses.

\subsection{RESEARCH PROBLEMS}

The study problem was to test the validity of the formed measurement model and reveal the correlations between the variables to enlighten the reasons for the students' academic procrastination behaviors.

\subsection{DATA COLLECTION METHOD}

Data were obtained through an online questionnaire form including four sections. The first section of the form included statements to obtain demographic data. The second section included the Social Media Usage Motives which was developed by Solmaz et al. (2013) and had 11 items to reveal the social media usage purposes of the participants. The third section included the Social Media Addiction Scale-Adult Form which was developed by Şahin and Yağc1 (2017) to determine the level of social media addiction of the participants. The last section of the form included the Academic 
Procrastination Scale which was developed by Aitken (1982) and was adopted to Turkish by Balkis (2006) to measure the academic procrastination behaviors of the participants. All statements except the statements used in the first section were presented to the participant with a 5-point Likert structure.

The population of the study included Osmaniye Korkut Ata University associate degree, undergraduate and postgraduate students, and the sample included 399 students who were reached by simple random sampling.

\subsection{QUANTITATIVE/QUALITATIVE ANALYSIS}

The Structural Equation Modeling (SEM) is a statistical method which enables the testing and verification of the effects between the observed and potential variables and which has a wide range of application areas. In other words, it examines the compatibility of a measurement model, which is considered to be conceptually valid with the obtained data and helps to verify or reject them (Şimşek Kandemir, 2019; Gürbüz, 2019).

SmartPLS 3.2.9 software was used for the application of variance-based structural equation model that works with the partial least squares method to test the presented model in the study. The validity of the study model and testing of the hypotheses were realized with this software (Doğan, 2019).

\subsection{RESEARCH MODEL}

This study examined the effect of social media addiction on social media usage purposes and academic procrastination behavior and the effects of social media usage purposes on academic procrastination behavior in the measurement model formed with the support of the literature. Additionally, the study checked the mediator effect of social media usage purposes on the relationship between social media addiction and academic procrastination behavior.

\subsection{RESEARCH HYPOTHESES}

The four determined hypotheses of the study are as follows;

$\boldsymbol{H}_{1}$ : Social media addiction has a positive significant effect on social media usage purposes.

$\mathrm{H}_{2}$ : Social media addiction has a positive significant effect on academic procrastination behavior.

$\mathrm{H}_{3}$ : Social media usage purposes have a positive significant effect on academic procrastination.

$\mathrm{H}_{4}$ : Social media usage purposes have a mediator effect between social media addiction and academic procrastination.

\section{FINDINGS AND DISCUSSION}

\subsection{FINDINGS as a RESULT of ANALYSIS}

The validity and reliability analyses of the scales were performed at first. Thus, the combination validity, internal consistency and disintegration validity were examined. Cronbach's alpha coefficient and Composite Reliability (CR) coefficient were taken into consideration for the internal consistency reliability. The factor loads and average variance extracted (AVE) were regarded for combination validity (Hair et al., 2017: 109). Three criteria were examined for disintegration validity. These criteria were cross loadings, Fornell-Larckerr table and HTMT values. The structures in the study received values at reference points of all criteria, and the internal consistency reliability, combination and disintegration validities of the structures were reached (Hair et al., 2017: 113; Doğan, 2019: 46).

PLS algorithm was used to determine the VIF values, effect size $\left(\mathrm{f}^{2}\right)$ and $\mathrm{R}^{2}$ values of the study model while Blindfolding analysis was used to determine its predictive power $\left(\mathrm{Q}^{2}\right)$. Considering $\mathrm{R}^{2}$ values in the analysis results, academic procrastination behavior and social media usage purposes were respectively explained at the rate of $37.5 \%$ and $27.7 \%$, and there was no linearity problem according to VIF values. Additionally, the model had predictive power on the variables of academic procrastination and social media usage purposes according to $\mathrm{Q}^{2}$ values. Considering the effect size $\left(\mathrm{f}^{2}\right)$ values, social media addiction had high effects on social media usage purposes while social media purposes had high effects on academic procrastination behavior; however, social media addiction had no effect on academic procrastination. Mediator effect analysis was made based on this finding. In the 
analysis, the effects were checked using 5000 sub-samples in bootstrap technique and VAF coefficient was calculated (Zhao et al., 2010; Hair et al., 2014). VAF values for the related correlation was calculated as 1.04 (indirect effect $=0.326$ and direct effect $=0.013$ ) and social media usage purposes were found to have complete mediatory effect on this correlation.

\subsection{HYPOTHESIS TEST RESULTS}

The study supported $\mathrm{H}_{1}$ hypothesis which states that social media addiction has a positive significant effect on social media usage purposes $(\beta=0.527, \mathrm{p}<0.000)$ and $\mathrm{H}_{3}$ hypothesis $(\beta=0.619, \mathrm{p}<0.000)$ which states that social media usage purposes have a positive significant effect on academic procrastination. However, the study did not support $\mathrm{H}_{2}$ hypothesis $(\beta=-0.013, \mathrm{p}=0.854)$ which states that social media addiction has a positive significant effect on academic procrastination. The result of mediator effect analysis $\left(\mathrm{VAF}_{\mathrm{SMA}-\mathrm{SMUP}-\mathrm{AP}}=1.04\right)$ supported $\mathrm{H}_{4}$ hypothesis and showed that social media usage purposes had complete mediatory role on the relationship between social media addiction and academic procrastination.

\subsection{DISCUSSING the FINDINGS with the LITERATURE}

In line with the studies in the literature, the study results showed that social media usage purposes had a direct positive effect on social media addiction (Çömlekçi and Başol, 2019; Idubor, 2015; Filiz et al., 2014). The variable of social media usage purposes had a direct positive effect on the variable of academic procrastination behavior. Accordingly, the study stated that the quality of the students' social media usages was also important. Unlike the literature, the study revealed that social media addiction had no direct positive effect on academic procrastination behavior (Gürültü, 2016; Gür et al., 2018; Teyfur, 2017; Demir and Kutlu, 2017). Therefore, the study performed an analysis according to the mediator analysis conditions determined by Zhao et al. (2010) and determined the presence of a mediator effect.

\section{CONCLUSION, RECOMMENDATION AND LIMITATIONS}

\subsection{RESULTS of the ARTICLE}

The analysis findings showed that the proposed measurement model in the study can be used. The study data showed that students' social media addiction is mainly due to reaching information and staying up-to-date and that their social media usage purposes tend to be accessing to information and staying up-to-date as well as spending free leisure time and communicating. The study revealed that social media addiction affected social media usage purposes while it positively affected academic procrastination behavior. Accordingly, the study deducted that complete mediatory effect of the variable of social media usage purposes was comprehensible.

\subsection{SUGGESTIONS BASED on RESULTS}

Future studies can perform supportive analyses that explain the mediatory effect in the model. Additionally, different variables can be added to the model and mediatory effect in the variables can be examined.

\subsection{LIMITATIONS of the ARTICLE}

The sample form which the data were obtained has the ability to represent the universe using the simple random sampling method to generalize to cover all students. 


\section{GİRIŞ}

Dünyada gelişen telekomünikasyon teknolojileri ve göreceli ucuzlayan bu teknolojilere erişim fiyatları dolayısıyla bireylerin internet erişimleri giderek artan bir ivmeye sahiptir. Türkiye İstatistik Kurumu (TÜIK) tarafından 2017-2018 yılları arasında yapılan araştırmalara göre Türkiye' de evden internete bağlanabilme oranı sürekli olarak yükselmiştir (\%80,7 - \%83,8 - \%88,3). Benzer biçimde mobil teknolojilerin hızla yaygınlaşmasının bir sonucu olarak yorumlanabilecek bir veri olan 16-74 yaş aralığındaki bireylerin internet kullanımları 2017-2019 dönemlerinde (\%66,8 - \%72,9 - \%75,3) sürekli artış göstermiştir (TÜiK, 2018; TÜiK, 2019).

Yine TÜiK verilerinde 16-74 yaş arası bireylerden araştırmaya dahil olanların internet kullanımlarındaki amaçlar ile ilgili tablolar incelendiğinde, 2017 yılında ilgili bireylerin son üç ay içerisinde internet kullanım amaçları tablosunda \%83,7 gibi büyük bir oran ile sosyal medya kullanımı ilk sırada yer almıştır. Aynı veri 2018 yılında yine kullanım amaçlarının ilk sırasında olmakla birlikte $\% 84,1$ oran ile ve 2019 yılında üçüncü sırada \%81,4 oran ile seçilmiştir (TÜiK, 2018; TÜIK, 2019).

Benzer biçimde Hootsuite ve We Are Social (2020) tarafından yayınlanan raporda Türkiye'de 16-64 yaş grubundan araştırmaya dahil olan kişilerin \%64'ünün sosyal medya erişiminin olduğu ve internet kullanıcılarının bir günde internette geçirdiği sürenin yaklaşık \%40'ında sosyal medya ile meşgul olduğu bildirilmiştir (Hootsuite ve We Are Social, 2020).

Bu bağlamda bireylerin internet kullanım alışkanlıklarında ilk sıralarda olan sosyal medya için literatürde karşılaşılabilecek tanımlardan bazıları metnin devamında aktarılmışır.

Akıncı Vural ve Bat (2010) tarafından sosyal medya, "zaman ve mekan sınırlaması olmadan (mobil tabanlı), paylaşımın, tartışmanın esas olduğu bir insani iletişim şekli" olarak tanımlanmıştır. Papacharissi (2015), sosyal medyanın tanımının dinamik olduğunu ve ancak bağlama özel olabileceğini bildirir. Başka bir tanıma göre sosyal medya, bireylerin, toplulukların ve kuruluşların kolay erişilebilen, bireysel ve katılımlı içerik oluşturmalarını-değiştirmelerini, paylaşmalarını ve etkileşim kurmalarını sağlayarak toplulukların ortak çalışmalarına, bağlantı 
kurmalarına olanak tanıyan web tabanlı hizmetlerdir (McCay-Peet ve Quan-Haase, 2017).

Farklı çalışmaların bireyler bazında inceledikleri sosyal medya kullanım amaçları içerisinde haber alma, iletişim, boş zaman aktivitesi/eğlence aracı olarak kullanım, bilgiye erişme amacıyla kullanım, eğitim ve araştırma amaçlı kullanım ve siyasi amaçlı kullanım maddeleri bulunmaktadır (Çömlekçi ve Başol, 2019; Acun vd., 2017; Akıncı Vural ve Bat, 2010; Taşçı ve Ekiz, 2018).

Sosyal medya kullanımının bu denli çeşitlendirilebilmesi ve günlük hayatın her anına dokunabilmesi sebebiyle sosyal medya bağımlılığı kavramının bilimsel çalışmalar yapan yazarların dikkatini çekmesi beklenen bir sonuç olarak karşılanmaktadır.

Bağımlılık, bireyin herhangi bir madde veya tekrarlanan bir davranış için kontrolünü kaybetmesi olarak tanımlanabilir. Temelde giderek güçlenen ve bireye ilgili davranışı yapma - ilgili maddeyi kullanma güdüsü sağlayan bağımlılık, yapma veya kullanma sonrasında bireyi ulaştırdı̆̆ı rahatlama ve doyuma karşın yapmama veya kullanmama durumunda sürüklediği huzursuzluk ile belirginleşmektedir. Türkiye Bağımlılıkla Mücadele Eğitim Programı (TBM) tarafından verilmiş olan tanımdan da anlaşılacağı üzere bağımlılık olgusu genel görünüşünün aksine yalnızca bir maddeye odaklı olarak ortaya çıkmamaktadır (TBM Uygulayıcı https://uygulayici.tbm.org.tr/, 2020).

Genel itibarda bilişsel, duygusal ve davranışsal kaynaklı olarak üç tür bağımlılıktan söz etmek mümkündür. Bilişsel bağımlılık hissedilen bir bilgi boşluğunun doldurulması için bilgiye ihtiyaç duyma halidir. Duygusal bağımlılık, kişilerin gereksinimlerinden olan sosyallik veya sosyallikten kaçma ihtiyacını gidermeye yönelik sosyal ağlar kullanma olarak açıklanmaktadır. Davranışsal bağımlılık ise eylemsel ve araçsal olarak iki şekilde ortaya çıkabilmektedir. Dolayısıyla davranışsal bağımlılığı kullanılan araç veya araçlara bağlı içeriğe olan bağl1lık olarak açıklamak mümkün olmaktadır. (Hazar, 2011; Kızılkaplan, 2018). Davranışsal bağımlılık türleri için internet, sosyal medya ve akıllı telefon bağımlılıkları örnekleri verilebilir. (Savcı ve Aysan, 2017). 
“İnternet bağımlılığı" kavramı, ilk defa Ivan Goldberg tarafından 1995 yılında kullanılmıştır ve problemli internet kullanımından dolayı ortaya çıkan durumu ifade etmektedir (Tutgun Ünal, 2015). İnternet bağımlılığının dijital oyun, sosyal medya ve akıllı telefon bağımlılı̆̆ı gibi kavramları da kapsadığı belirtilmektedir (Savcı ve Aysan, 2017). Bu durumun son yıllarda internet dünyasının sosyal ağlar ile son derece iç içe geçmesinin bir sonucu olarak değerlendirilebilmesi mümkündür.

Sosyal medya bağımlılığının madde bağımlılığı gibi diğer bağımlıkların bulgularına benzer bulgular gösterdiği söylenebilir. Tablo 1'de madde bağımlılı̆̆ı ve sosyal medya bağımlılığı bulguları arasındaki benzerlikler sunulmuştur (Savcı ve Aysan, 2017; Ayeni, 2019).

Tablo 1. Madde Bağımlılığı Bulguları ve Sosyal Medya Bağımlılı̆̆ı Bulguları

\section{Arasındaki Benzerlikler}

\begin{tabular}{|c|c|c|}
\hline & Madde Bağımlılı̆̆1 Bulguları & Sosyal Medya Bağımlılığı Bulguları \\
\hline 1 & $\begin{array}{l}\text { Bir madde veya madde kullanımı nedeniyle } \\
\text { sorumlulukların yerine getirememek }\end{array}$ & $\begin{array}{l}\text { Sosyal medya kullanımı nedeniyle işleri } \\
\text { geciktirmek, yemekleri yakmak veya küçük } \\
\text { çocukları korunmasız bırakmak }\end{array}$ \\
\hline 2 & $\begin{array}{l}\text { Maddenin neden olduğu sağlik problemleri } \\
\text { hakkında tam bilgi sahibi olma durumunda } \\
\text { bile maddeyi kullanmaya devam etmek. }\end{array}$ & $\begin{array}{l}\text { Aşırı sosyal medya kullanımı nedeniyle } \\
\text { yalnızlığa, baş ağrısına, uyku bozukluklarına, } \\
\text { aşırı kilolara veya obeziteye sahip olmak. }\end{array}$ \\
\hline 3 & $\begin{array}{l}\text { Madde kullanımı nedeniyle hukuki sorunlarla } \\
\text { karşılaşmak. }\end{array}$ & $\begin{array}{l}\text { Trafik polisi ile sorunlara yol açabilmesine } \\
\text { rağmen trafikte sosyal medya ile ilgilenmek. }\end{array}$ \\
\hline 4 & $\begin{array}{l}\text { Maddenin etkisindeyken veya maddeye } \\
\text { erişmeye çalışırken dikkatsiz davranmak. }\end{array}$ & $\begin{array}{l}\text { Veri satın almak için borçlanmak, önemli sosyal } \\
\text { medya güncellemelerini kaçırmama bahanesiyle } \\
\text { para çalmak. }\end{array}$ \\
\hline 5 & $\begin{array}{l}\text { Mide bulantısı, kusma, baş dönmesi, ruh } \\
\text { halindeki değişimler gibi madde } \\
\text { kullanılmadığında ortaya çıan yoksunluk } \\
\text { belirtileri. }\end{array}$ & $\begin{array}{l}\text { Basit talimatları anlayamama, konsantrasyon } \\
\text { eksikliği, telefonsuzken veya erişilemezken } \\
\text { mutsuz ve karamsar ruh hali. }\end{array}$ \\
\hline 6 & $\begin{array}{l}\text { İş, okul, aile buluşması, hobiler gibi sevilen } \\
\text { etkinlik veya sorumlulukları göz ardı etmek. }\end{array}$ & $\begin{array}{l}\text { Sosyal medya kullanırken aileyi ve diğer } \\
\text { sevilenleri göz ardı etmek, yüz yüze } \\
\text { etkileşimdense yazışmayı veya telefonla } \\
\text { konuşmayı tercih etmek. }\end{array}$ \\
\hline 7 & $\begin{array}{l}\text { Maddeye ulaşmaya çalışırken veya kullanarak } \\
\text { iyi duruma gelmeye çalışırken çok fazla } \\
\text { zaman harcamak. }\end{array}$ & $\begin{array}{l}\text { Sosyal medyaya çok fazla zaman ayırmak, her } \\
10 \text { veya } 15 \text { dakikada bir telefonda bildirim olup } \\
\text { olmadığını kontrol etmek. }\end{array}$ \\
\hline 8 & $\begin{array}{l}\text { Maddenin kişinin istediğinden daha fazla } \\
\text { alınması, bırakmaya çalışıldığında } \\
\text { bırakılamaması, öz kontrol kaybı. }\end{array}$ & $\begin{array}{l}\text { Arkadaşların veya ailelerin şikâyetlerine } \\
\text { rağmen sosyal medya kullanımını kontrol } \\
\text { edememek. }\end{array}$ \\
\hline
\end{tabular}

Tablo 1'de görüldüğü üzere sosyal medya bağımlılığının bulguları arasında aşırı kullanım nedeniyle işleri geciktirmek, sorumlulukları yerine getirememek gibi maddeler bulunmaktadır. Öğrenciler için bu durumun akademik sorumlulukları 
geciktirmek, ertelemek olarak ortaya çıkabilmesi muhtemeldir. Dolayısıyla sosyal medya bağımlılığının akademik erteleme davranışını yordayan değişkenlerden olabileceği düşünülmekte ve bu çalışmada incelenmektedir.

Akademik erteleme davranışı, erteleme davranışının türlerinden biridir. $\mathrm{Bu}$ türler arasında genel erteleme, karar almayı erteleme, nevrotik erteleme ve takıntılı erteleme de bulunmaktadır (Balkıs vd., 2006). Klassen ve Kuzucu (2009) tarafindan erteleme, tasarlanan bir eylemin bilinçli olarak ve mantıksızca geciktirilmesi olarak tanımlanmış, genelde beklenmeyen performans düşüklüğü ve mutsuzluk sonuçlarını doğuracağ1 belirtilmiştir (Klassen ve Kuzucu, 2009). Solomon ve Rothblum (1984) ertelemenin kişilerin, sorumluluklarını kendilerini rahatsız edecek duruma gelene dek ötelemesi sorunu olduğunu belirtmişlerdir.

Sosyal medya, işlevselliği nedeniyle kullanım amaçları yönünden incelenmeye elverişli bir alandır. Literatürde sosyal medyanın kullanımı ile ilgili farklı örneklemlere uygulanmış fazlaca çalışma bulunmaktadır. Bu çalışma, sosyal medyanın öğrencilerin akademik hayatlarına olan etkileri ile ilgilenecektir. Modelde yer verilen sosyal medya konuları ile ilgili geçmişte yapılmış çalışmalardan bazıları aşağıda açıklanacaktır.

Çömlekçi ve Başol (2019) tarafından yapılan çalışmada gençlerin sosyal medya kullanım amaçları ile sosyal medya bağımlılıkları arasındaki ilişkinin ortaya çıkarılması amaçlanmıştır. Çalışmanın sonuçlarında kullanım amaçlarından bazıları ile sosyal medya bağımlılığı arasında anlamlı ilişkiler bulguları sunulmuştur.

Akın (2017) tarafından yapılan çalışmada gençlerin internet bağımlılığı derecelerinin sosyal medya kullanım amaçlarını etkileyip etkilemediğini ortaya koymak amaçlanmıştır. İncelenen ilişkinin anlamlı olarak ortaya konduğu açıklanmıştır.

Idubor (2015), çalışmasında Nijerya'da bir üniversitenin lisans öğrencilerinin sosyal medya kullanımını ve bağımlılığını incelemiştir. Sonuçlara göre; lisans öğrencilerinde sosyal medya kullanım alışkanlıkları ile sosyal medya bağımlılığı derecesi arasında anlamlı ilişki bulunmuştur. 
Filiz vd. (2014) tarafından yapılan çalışmada, eğitim fakültesinde öğrenim gören 178 öğrenciye bir anket formu uygulanarak öğrencilerin sosyal ağları kullanım amaçları ve internet bağımlılıkları arasındaki ilişkilerin açıklanması amaçlanmıştır. Uygulanan korelasyon analizinin bulgularına göre incelenen ilişkinin orta derecede anlamlı olduğu belirtilmiştir.

İlgili çalışmalardan hareketle sosyal medya kullanım amaçları ve sosyal medya bağımlılığı ilişkisine yönelik geliştirilmiş olan hipotez şu şekildedir:

H1: Sosyal medya bağımlılı̆̆ı sosyal medya kullanım amaçlar üzerinde pozitif yönlü anlamlı bir etkiye sahiptir.

Öğrencilerin akademik erteleme davranışlarında etkili olan olası nedenlerden bazıları değerlendirilme endişesi, mükemmeliyetçilik, zorlu karar verme, bağımlılık ve destek isteme, görev nitelikleri ve hayal kırıklığına karşı dirençsizlik, özgüven eksikliği, tembellik, iddiasız olmak, başarı korkusu, zaman yönetimi başarısızlığı, kontrole karşı isyan, risk almama ve yaşıtların etkisi olarak sayılmıştır (Solomon ve Rothblum, 1984). Ancak yakın dönem çalışmalarından anlaşıldı̆̆ı üzere akademik erteleme davranışı ve sosyal medya bağımlılığı arasındaki ilişki anlamlı olabilmektedir. Bu çalışmalardan bazıları açıklanacaktır.

Durdu (2019) çalışmasında, ortaokul derecesinde eğitim gören öğrencilerin sosyal medya bağımlılık düzeyleri ile akademik erteleme davranışlarının ilişkisini incelemeyi amaç edinmiştir. Kavramlar arasında anlamlı bir ilişkinin varlığının kontrol edilmesi için korelasyon analizi uygulanıp sonucunda pozitif yönde orta düzeyde anlamlı ilişki tespit edilmiştir.

Yurdakoş ve Biçer (2019) tarafından yapılan çalışmada öğrencilerin internet bağımlılığı düzeyinin akademik erteleme davranışları üzerindeki etkisinin ölçülmesi amaçlanmaktadır. Uygulanan ANOVA, korelasyon analizi, regresyon analizi ve ttesti gibi istatistiki yöntemler sonucunda incelenmesi amaçlanmış olan ilişki doğrulanmış, internet bağımlılığı değişkeninin akademik erteleme davranışı değişkeni üzerinde anlamlı bir etkiye sahip olduğu ortaya konmuştur.

Gür vd. (2018) çalışmalarında amaçlarını, üniversite öğrencilerinin sosyal medya bağımlılıklarının akademik erteleme davranışları ile olan ilişkisinin 
incelenmesi olarak belirlemişlerdir. Uygulanan varyans analizi sonucunda öğrencilerin sosyal medya bağımlılık düzeylerinin akademik erteleme davranışları ile ilişkili olduğu ortaya konmuştur.

Teyfur vd. (2017) çalışmalarında, öğretmen adaylarının sosyal medya bağımlılığı ve akademik erteleme davranışları arasındaki ilişkiyi incelemeyi amaçlamışlardır. Sosyal medya bağımlılık ölçeğinin alt boyutları ile akademik erteleme ölçeği puanları arasındaki ilişki korelasyon analizi ile test edilmiş ve tüm boyutlar için pozitif yönde anlamlı ilişki görüldüğü belirtilmiştir.

Demir ve Kutlu (2017) çalışmalarında lise öğrencilerinin internet bağımlılı̆̆ı, akademik başarı durumu ve akademik erteleme davranışlarının ilişkilerini incelemişlerdir. Çalışmanın sonucunda internet bağımlılı̆̆ının akademik erteleme davranışı üzerinde pozitif yönlü ve akademik erteleme davranışının akademik başarı üzerinde negatif yönlü etkiye sahip olduğu belirtilmiştir.

Gürültü (2016), çalışmasında lise öğrencilerinde sosyal medya bağımlılı̆̆1 ve akademik erteleme ilişkisini incelemiştir. Yapılan analiz sonucunda incelenen ilişkinin anlamlı olduğu ortaya konmuştur.

İncelenen çalışmalardan hareketle sosyal medya bağımlılığı ve akademik erteleme davranışı arasındaki ilişki için kurulmuş olan hipotez şu şekildedir:

$\mathbf{H}_{2}$ : Sosyal medya bağımlılı̆̆ı akademik erteleme davranışı üzerinde pozitif yönlü anlamlı bir etkiye sahiptir.

Sosyal medya kullanım amaçları ölçeği ile akademik erteleme davranışı ölçeği arasındaki ilişki 3 numaralı hipotez ile kontrol edilmektedir.

$\boldsymbol{H}_{3}$ : Sosyal medya kullanım amaçları akademik erteleme üzerinde pozitif yönlü anlamlı bir etkiye sahiptir.

Son olarak bu çalışmada sosyal medya kullanım amaçları ölçeği ile akademik erteleme ölçeği arasındaki ilişkide sosyal medya bağımlılı̆̆ı ölçeğinin rolü incelenecektir. Bu amaç için kurulmuş olan hipotez ise şu şekildedir: 


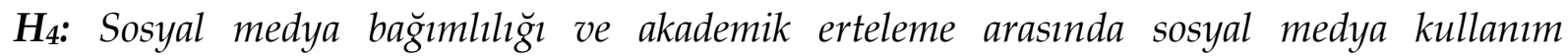
amaçlarının aracı etkisi vardır.

Çalışmada incelenen model Şekil 1'de sunulmaktadır.

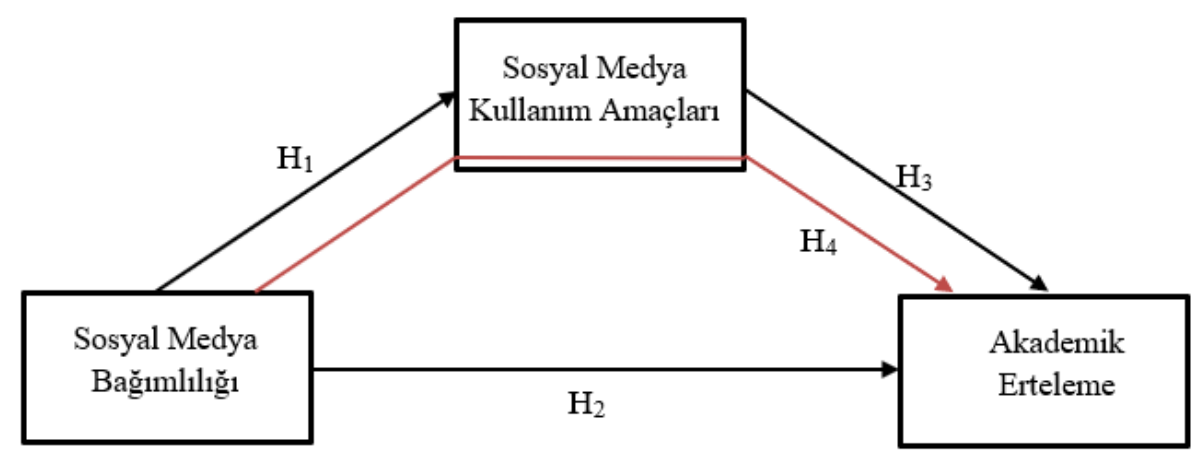

Şekil 1. Araştırma Modeli

\section{YÖNTEM}

Psikoloji, sağlık, yönetim organizasyon gibi çeşitlendirilebilen birçok uygulama alanlarına sahip olan Yapısal Eşitlik Modellemesi (YEM), gözlenen ölçülebilen- ve gizil -doğrudan ölçülemeyen- değişkenler arasındaki etkilerin test edilerek doğrulanabilmesine olanak veren bir istatistiksel yöntemdir. Diğer bir deyişle kavramsal olarak geçerli kabul edilen bir ölçüm modelinin elde edilen veri ile uyumunu araştırır, doğrulanmasına veya reddine karar vermeye yardım eder. Regresyon ve faktör analizlerinin bir versiyonu olarak da görülen bu analiz yönteminin farkı; birden çok bağımlı ve bağımsız değişken arasındaki etki modeli gibi karmaşık ilişkiler ile ilgilenmesidir. Bunun yanı sıra ikinci nesil bir analiz yöntemi olması da bir fark olarak gösterilebilir (Şimşek Kandemir, 2019; Gürbüz, 2019).

Geçerlik ve güvenirlik analizleri kapsamında iç tutarlılık güvenirliği, birleşme geçerliği ve ayrışma geçerliğinin sağlandı̆̆ 1 kontrol edildikten sonra modelin doğrusallığı, yol katsayıları, etki büyüklüğünü $\left(\mathrm{f}^{2}\right)$ ve $\mathrm{R}^{2}$ 'sini hesaplamak için kısmi en küçük kareler yöntemi (Partial Least Squares - PLS) algoritması kullanılmıştır.

\subsection{Kullanılan Veri Toplama Araçları}

Araştırmanın verileri online anket yöntemi ile elde edilmiştir. Veri toplamak üzere kullanılan form, dört bölümden oluşacak biçimde oluşturulmuştur. Formun ilk 
bölümünde katılımcılardan cinsiyet, yaş gibi genel geçer demografik verilerin yanı sira en sık kullanılan sosyal medya platformu, gün içerisinde sosyal medyada geçirilen zaman, haber almak üzere kullanılan sosyal medya platformu ve akademik katkı yönünden tercih edilen sosyal medya platformu gibi sonuçları özelleştirmede fayda sağlayacak bilgiler de alınmıştır.

Formun ikinci bölümünde, katılımcıların sosyal medyayı kullanım amaçlarının ortaya çıkarılması için Solmaz vd. (2013) tarafından geliştirilen, Çömlekçi ve Başol'un (2019) geçerlik ve güvenirlik analizleri sonucunda 3 maddesi kapsam dışı bırakılarak 11 maddede değerlendirilen "Sosyal Medya Kullanım Amaçları Ölçeği" kullanılmıştır.

Anket formunun üçüncü bölümünde, katılımcıların sosyal medya bağımlılık derecesini belirlemek üzere, Şahin ve Yağcı (2017)'nın geliştirilmiş olduğu “Sosyal Medya Bağımlılığı Ölçeği - Yetişkin Formu" ifadeleri kullanılmıştır. İlgili ölçek 20 madde ve 2 boyuttan meydana gelmektedir. Bu boyutlardan ilki 11 madde ile ifade edilen sanal tolerans boyutu, ikincisi de 9 madde ile ifade edilen sanal iletişim boyutudur.

Anket formunun son bölümünde ise katılımcıların akademik erteleme davranışlarını ölçen, Aitken (1982) 'in geliştirdiği ve Balkıs (2006) 'ın Türkçe'ye uyarladığ1 “Akademik Erteleme Eğilimi Ölçeği” kullanılmıştır. İlgili ölçek orijinal versiyonunda tek boyutta toplanan 19 madde iken Balkıs (2006) tarafından yapılan uyarlama çalışması sırasında 16 maddeye indirgenmiştir.

Katılımcılara sunulan formun ilk bölümü dışındaki tüm bölümlerinde 1 Kesinlikle Katılmıyorum ve 5 - Kesinlikle Katılıyorum şeklinde beş puanlı Likert yapı kullanılmıştır. Demografik bölümde ise değişkenler kategorik yapıda sunulmuştur.

Anket formunun uygulanması için Osmaniye Korkut Ata Üniversitesi Bilimsel Araştırma ve Yayın Etiği Kurulu tarafından 13.03.2020 tarihinde, 59754796-050.99/ sayılı yazı ve 2020/11/2 sayılı karar ile Etik Kurul Onayı verilmiştir. 


\section{1. Örneklem}

Çalışmanın anakütlesi, Osmaniye Korkut Ata Üniversitesinde kayıtlı öğrencilerden oluşmaktadır. Anakütleyi temsil edecek örneklemin \%95 güven aralığında yaklaşık 366 birimden oluşması gerektiği hesaplanmıştır (Surveysystem, 2016).

Anketin uygulanacağı öğrenciler basit tesadüfi örnekleme yöntemi ile önlisans, lisans ve lisansüstü öğrencileri içinden belirlenmiştir. Öğrencilerden toplanan 399 adet anket verisi ile çalışılmıştır. Elde edilen verilere göre ulaşılan gözlemlerin demografik dağılımları Tablo 2'de sunulmaktadır.

Tablo 2. Katılımcıların Demografik Özellikleri

\begin{tabular}{llllll}
\hline Yaş & $\mathbf{N}$ & $\mathbf{0}$ & Cinsiyet & $\mathbf{N}$ & $\mathbf{\%}$ \\
\hline $18-20$ & 56 & 14 & Kadın & 169 & 42.2 \\
\hline $21-23$ & 237 & 59.2 & Erkek & 230 & 57.8 \\
\hline $24-26$ & 63 & 15.8 & & & \\
\hline $27-29$ & 13 & 3.5 & & & \\
\hline $30+$ & 30 & 7.5 & & & \\
\hline
\end{tabular}

\section{VERİLERIN ANALIZİ}

Çalışmada literatür araştırması sonucunda değerlendirilmesi uygun görülen modelin test edilmesi amacıyla kısmi en küçük kareler yöntemi ile çalışan varyans temelli yapısal eşitlik modeli uygulaması için SmartPLS 3.2.9 yazılımı kullanılmıştır. $\mathrm{Bu}$ yazılım ile araştırma modelinin geçerliliği ve hipotezlerin doğruluğu test edilmiştir (Doğan, 2019).

\subsection{Geçerlilik ve Güvenilirlik Analizleri}

Modelin geçerliliğinin analizinden önce ölçekler için geçerlik ve güvenirlik çalışmaları gerçekleştirilmiştir. Bu kapsamda birleşme geçerliği, iç tutarlılık güvenirliği ve ayrışma geçerliği incelenmiştir. İç tutarlılık güvenilirliği için Cronbach Alpha katsayısı ve birleşik güvenilirlik katsayısı (Composite Reliability - CR) katsayısı dikkate alınır. Her iki katsayıdan da benzer şekilde 0.70 ile 0.90 arasında değer alması beklenir. 0.95'in üzerinde Cronbach Alpha değeri ise değişkenlerin ölçtükleri durumlar arasında fazla benzerlik olduğuna işarettir (Hair vd., 2017). 
Birleşme geçerliliği için ifadelerin faktör yüklerine ve açıklanan ortalama varyans değerlerine (Average Variance Extracted - AVE) dikkat edilmiştir. İfadelerin faktör yüklerinin 0.70 veya daha büyük bir değere sahip olması gerektiği bilinmektedir. Ancak özellikle sosyal bilimlerde her zaman bu değere ulaşmak kolay olmayabilir. Faktör yüklerinin 0.40 ile 0.70 aralığında olması durumunda ilgili ölçeğin AVE değerinin sınır değer olan 0.50 ve üzeri olarak görülmesi gerekmektedir. Aksi halde faktör yükleri 0.70 'in altında olan ifadeler analiz kapsamindan çıkarılmalıdır (Hair vd., 2017, s. 109).

Tablo 3. Ölçüm Modeli Sonuçları

\begin{tabular}{|c|c|c|c|c|c|}
\hline Değişken & İfade & $\begin{array}{l}\text { Faktör } \\
\text { Yükü }\end{array}$ & $\begin{array}{c}\text { Cronbach } \\
\text { Alpha }\end{array}$ & $\begin{array}{l}\text { Birleşik } \\
\text { üvenilirlik } \\
\text { (CR) }\end{array}$ & $\begin{array}{c}\text { Açıklanan Ortalama } \\
\text { Varyans (AVE) }\end{array}$ \\
\hline \multirow{9}{*}{$\begin{array}{c}\text { Akademik } \\
\text { Erteleme (AE) }\end{array}$} & AE2 & 0.753 & & & \multirow{9}{*}{0.546} \\
\hline & $\mathrm{AE} 4$ & 0.635 & & & \\
\hline & AE9 & 0.817 & & & \\
\hline & AE10 & 0.738 & & & \\
\hline & AE12 & 0.725 & & 0.915 & \\
\hline & AE13 & 0.641 & & & \\
\hline & AE14 & 0.724 & & & \\
\hline & AE15 & 0.794 & & & \\
\hline & AE16 & 0.800 & & & \\
\hline \multirow{4}{*}{$\begin{array}{l}\text { Sosyal Medya } \\
\text { Bağımlılığ1 } \\
\text { (BG) }\end{array}$} & BG12 & 0.770 & & \multirow{4}{*}{0.824} & \multirow{4}{*}{0.541} \\
\hline & BG14 & 0.806 & & & \\
\hline & BG16 & 0.656 & & & \\
\hline & BG20 & 0.701 & & & \\
\hline \multirow{7}{*}{$\begin{array}{l}\text { Sosyal Medya } \\
\text { Kullanım } \\
\text { Amaçları (KA) }\end{array}$} & KA2 & 0.672 & \multirow{7}{*}{0.877} & \multirow{7}{*}{0.878} & \multirow{7}{*}{0.512} \\
\hline & KA3 & 0.552 & & & \\
\hline & KA7 & 0.901 & & & \\
\hline & KA8 & 0.669 & & & \\
\hline & KA9 & 0.717 & & & \\
\hline & KA10 & 0.637 & & & \\
\hline & KA11 & 0.807 & & & \\
\hline
\end{tabular}

Tablo 3, analiz sonucunda elde edilen faktör yüklerini, ölçeklerin Cronbach Alpha katsayılarını, birleşik güvenilirlik değerlerini ve açıklanan ortalama varyans değerlerini göstermektedir. Modeldeki yapıların Cronbach Alpha katsayıları 0.825 ile 0.916 arasında ve birleşik güvenilirlik katsayılarının da 0.824 ile 0.915 arasında gerçekleşmesi sebebiyle iç tutarlılık güvenilirliğinin sağlandığı görülmektedir. Ayrıca 
ifadelerin faktör yüklerinin 0.552 ile 0.901 arasında ve yapıların AVE değerlerinin de 0.512 ile 0.546 arasında gerçekleşmesi sebebiyle birleşme geçerliğinin sağlandığını belirtmek mümkündür.

Ayrışma geçerliliğinin tespit edilmesi için kullanılabilecek üç kriter bulunmaktadır. Bunlardan ilki çapraz yükleme (cross-loading) değeridir. Bu kritere göre bir ifadenin altında yer aldığı değişkene ait faktör yükü diğer değişkenlerde aldığı faktör yükünden daha yüksek olmalıdır. Kriterlerden bir diğeri FornellLarcker kriteridir. Fornell-Larcker tablosunda AVE değerlerinin karekökleri olan değerler diğer değişkenlerin değerleri ile karşılaştırılır ve köşegen değerlerin en büyük olması beklenir. Başka bir alternatif olan HTMT kriteri, değişkenlerin ifadelerinin korelasyonlarının geometrik ortalamalarını ifade etmektedir. HTMT kriterinin eşik değeri teorik olarak yakın kavramlar için 0.90 ve altı, yakın olmayan kavramlar için 0.85 ve altı olarak belirtilebilir (Hair vd., 2017, s. 113; Doğan, 2019, s. 46).

Tablo 4. Fornell-Larcker Kriteri Değerleri

\begin{tabular}{llll}
\hline & Akademik Erteleme (AE) & $\begin{array}{l}\text { Sosyal Medya Bağımlılı̆̆1 } \\
(\mathrm{BG})\end{array}$ & $\begin{array}{l}\text { Sosyal Medya Kullanım } \\
\text { Amaçları (KA) }\end{array}$ \\
\hline$(\mathrm{AE})$ & $\mathbf{0 . 7 3 9}$ & - & - \\
\hline$(\mathrm{BG})$ & 0.314 & $\mathbf{0 . 7 3 6}$ & - \\
\hline$(\mathrm{KA})$ & 0.612 & 0.527 & $\mathbf{0 . 7 1 6}$ \\
\hline
\end{tabular}

Tablo 4, Fornell-Larcker kriteri değerlerini, Tablo 5 ise HTMT kriteri değerlerini göstermektedir.

Tablo 5. HTMT Kriteri Değerleri

\begin{tabular}{llll}
\hline & Akademik Erteleme (AE) & $\begin{array}{l}\text { Sosyal Medya Bağımlılı̆̆ } \\
(\mathrm{BG})\end{array}$ & $\begin{array}{l}\text { Sosyal Medya Kullanım } \\
\text { Amaçları (KA) }\end{array}$ \\
\hline$(\mathrm{AE})$ & - & - & - \\
$(\mathrm{BG})$ & 0.309 & - & - \\
$(\mathrm{KA})$ & $\mathbf{0 . 6 0 6}$ & 0.526 & - \\
\hline
\end{tabular}

Tablo 4 ve Tablo 5'te görülen değerlerin eşik değerleri sağlaması dolayısıyla yapıların ayrışma geçerliliğinin sağlandığı ifade edilebilir.

\subsection{Model Analizi}

Araştırmanın konusu olan yapısal eşitlik modeli Şekil 2' de gösterilmektedir. 


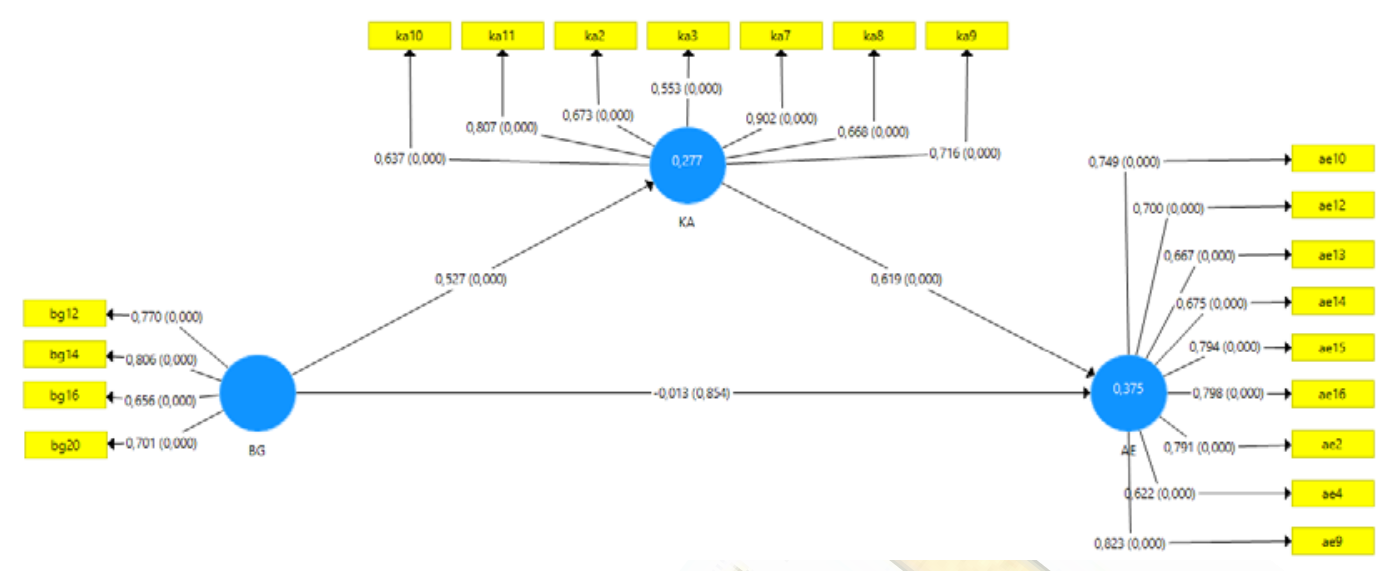

Şekil 2. Çalışmanın Yapısal Eşitlik Modeli

Araştırma modelinin VIF değerlerini, etki büyüklüğü $\left(\mathrm{f}^{2}\right)$ ve $\mathrm{R}^{2}$ değerlerini belirlemek amacıyla gerçekleştirilen PLS algoritması ve tahmin gücünün $\left(\mathrm{Q}^{2}\right)$ belirlenmesi için gerçekleştirilen Blindfolding analizinin sonuçları Tablo 6'da gösterilmiştir.

Tablo 6. Model Katsayıları

\begin{tabular}{|c|c|c|c|c|c|}
\hline \multicolumn{2}{|c|}{ Değişkenler } & VIF & $\mathbf{R}^{2}$ & $\mathbf{f}^{2}$ & $\mathrm{Q}^{2}$ \\
\hline $\begin{array}{c}\text { Sosyal Medya } \\
\text { Kullanım } \\
\text { Amaçları (KA) }\end{array}$ & $\begin{array}{l}\text { Sosyal Medya } \\
\text { Bağımlılığ1 (BG) }\end{array}$ & 1.000 & 0.277 & 0.384 & 0.116 \\
\hline \multirow[b]{2}{*}{$\begin{array}{c}\text { Akademik } \\
\text { Erteleme (AE) }\end{array}$} & Sosyal Medya & 138 & \multirow[b]{2}{*}{0.375} & 0.002 & \multirow[b]{2}{*}{0.177} \\
\hline & $\begin{array}{l}\text { Sosyal Medya } \\
\text { Kullanım } \\
\text { Amaçları (KA) }\end{array}$ & 1.384 & & 0.443 & \\
\hline
\end{tabular}

Değişkenlerin VIF katsayıları üst sınır olan 5 değerinin altında kaldığ1 için doğrusallık problemi yaşanmadığı ifade edilebilir (Hair vd. 2017: 138). Ayrıca $\mathrm{R}^{2}$ değerlerine bakılarak da akademik erteleme davranışının \%37,5 ve sosyal medya kullanım amaçlarının \%27,7 oranları ile açıklandığı anlaşılmaktadır.

Tablo 6'da gösterilen etki büyüklüğü değeri 0,02 ise düşük, 0,15 ise orta ve 0,35 ise etki yüksek olarak tanımlanmakta ancak 0,02 altındaki değerler için etkiden söz etmek mümkün olmamaktadır (Doğan, 2019, s. 51). Bu doğrultuda sosyal medya bağımlılığının sosyal medya kullanım amaçları üzerinde ve sosyal medya amaçlarının akademik erteleme davranışı üzerinde etkilerinin yüksek olduğu, sosyal 
medya bağımlılığının akademik erteleme davranışı üzerinde etkisinin olmadığı belirlenmiştir. Bu iki değişken arasında aracı değişken ilişkisi kontrol edilecektir.

Kısmi tahmin gücünü olarak anılan $\mathrm{Q}^{2}$ değeri de tıpkı $\mathrm{f}^{2}$ değeri gibi değerlendirilmekte olup her bir endojen değişkenin tahmin gücünü belirtmektedir (Doğan, 2019: 52). Buna göre model, akademik erteleme ve sosyal medya kullanım amaçları değişkenleri üzerinde tahmin gücüne sahiptir.

Tablo 7. Modelin Doğrudan Yol Katsayıları

\begin{tabular}{ccccc}
\hline & Standardize $\boldsymbol{\beta}$ Katsayısı & Standart Sapma & t değeri & P değeri \\
\hline BG -> AE & -0.013 & 0.073 & 0.185 & 0.854 \\
\hline BG -> KA & 0.527 & 0.056 & 9.425 & $0.000^{*}$ \\
\hline KA -> AE & 0.619 & 0.071 & 8.675 & $0.000^{*}$ \\
\hline & & $\mathrm{p}<0.01^{*}$ & &
\end{tabular}

Tablo 7' de modele ilişkin yol katsayılarının anlamlı olup olmadığı testlerinin sonuçları listelenmiştir. Buna dayanarak sosyal medya bağımlılı̆̆ının sosyal medya kullanım amaçları üzerinde pozitif yönlü anlamlı bir etkisi olduğunu ifade eden $\mathrm{H}_{1}$ hipotezi $(\beta=0.527, p<0.000)$ ve sosyal medya kullanım amaçlarının akademik erteleme üzerinde pozitif yönlü anlamlı bir etkisi olduğunu ifade eden $\mathrm{H}_{3}$ hipotezinin $(\beta=0.619, \mathrm{p}<0.000)$ desteklendiği anlaşılmıştır. Buna karşın sosyal medya bağımlılığının akademik erteleme üzerinde pozitif yönde anlamlı bir etkisinin olduğunu ifade eden $\mathrm{H}_{2}$ hipotezinin $(\beta=-0.013, \mathrm{p}=0.854)$ desteklenmediği sonucuna ulaşılmıştır.

\subsection{Aracı Etki Analizi}

Araştırma modelinde yer alan ilişkilerde aracı etkilerin kontrol edilmesi için Baron ve Kenny (1986) 'e göre modelin üç kısıta uyması gerekmektedir. Bu kısıtlar bağımlı değişken ve bağımsız değişken arasında, bağımlı değişken ve aracı değişken arasında, aracı değişken ile de bağımlı değişken arasındaki ilişkilerin anlamlı olması gerektiğidir. Ancak bağımsız değişken ile bağımlı değişken arasında anlamlı ilişki olması kısıtı eleştiri alabilmektedir. Zhao vd. (2010), bu kısıt sağlanmasa bile aracı etkinin söz konusu olabileceğini belirtmişlerdir (Doğan, 2019, s. 104). 
Araştırmanın ikinci kısmında Zhao vd. (2010)'ne dayanarak sosyal medya kullanım amaçları değişkeninin aracılık etkisi kontrol edilmektedir. Bu aşamada bootstrap tekniği 5000 alt örneklem kullanılarak etkiler kontrol edilmiş, VAF katsayısı hesaplanmıştır. VAF katsayısı aracılık etkisi kontrol değeri olup $\boldsymbol{V A F}=$ $\frac{\text { Dolaylı Etki }}{\text { Dolayl Etki+Doğrudan Etki }}$ formülü ile hesaplanmaktadır. Eğer VAF değeri \%20'den küçük ise herhangi bir aracı etkiden söz etmek mümkün olmaz iken, değer \%20 ile \%80 arasında olduğu durumda kısmi aracı etki ve \%80'den büyük olduğu durumda tam aracı etki gözlemlenmiş olarak yorumlanmaktadır (Hair vd., 2014, s. 225).

Araştırmanın son hipotezi olan $\mathrm{H}_{4}$ hipotezi için sosyal medya bağımlılı̆̆ değişkeni ile akademik erteleme davranışı değişkeni arasındaki ilişkide sosyal medya kullanım amaçları değişkeninin aracı etkisi kontrol edilmiştir. İlgili ilişki için VAF değeri 1,04 olarak hesaplanmış (dolaylı etki=0.326 ve doğrudan etki=-0.013) ve tam aracılık etkisi olduğu kanısına ulaşılmıştır. Bu bulguya göre $\mathrm{H}_{4}$ hipotezi desteklenmiştir. Aracı etkiden sonra modele ilişkin yol katsayıları Tablo 8'de gösterildiği gibi olmuştur.

Tablo 8. Aracı Etkiden Sonra Modelin Yol Katsayıları

\begin{tabular}{lcccc}
\hline & Standardize $\boldsymbol{\beta}$ Katsayıs & Standart Sapma & $\mathbf{t}$ değeri & P değeri \\
\hline BG -> AE & 0.313 & 0.063 & 5.000 & $0.000^{*}$ \\
\hline BG -> KA & 0.527 & 0.056 & 9.425 & $0.000^{*}$ \\
\hline KA -> AE & 0.619 & 0.071 & 8.675 & $0.000^{*}$ \\
\hline & & $\mathrm{p}<0.01^{*}$ &
\end{tabular}

Tablo 8'e göre bağımsız değişken ile bağımlı değişken arasındaki ilişki de anlamlı hale gelmiştir.

\section{SONUÇ VE ÖNERİLER}

$\mathrm{Bu}$ çalışmada literatür araştırması sonucunda ulaşılmış olan sosyal medya bağımlılığı, sosyal medya kullanım amaçları ve akademik erteleme değişkenleri arasındaki ilişkiler incelenmiştir. Yöntem olarak yapısal eşitlik modellemesi kullanılmış, model üzerinden dört hipotez kurulmuştur. İki aşamada gerçekleştirilmiş olan analizlerde önce yapıların geçerlik ve güvenirlik analizleri yapılmış ardından geliştirilen hipotezler test edilmiştir. 
Değişkenlerin doğrudan etkileri incelendiğinde kurulan hipotezlerden ikisinin desteklendiği, birinin desteklenmediği görülmüştür. Literatürdeki çalışmalar ile paralel olarak sosyal medya kullanım amaçları değişkeninin sosyal medya bağımlılı̆̆ı değişkenine doğrudan pozitif bir etki yaptığ1 görülmüştür (Çömlekçi ve Başol, 2019; Idubor, 2015; Filiz vd., 2014). Literatürde görülenin aksine sosyal medya bağımlılığının akademik erteleme davranışı üzerinde doğrudan pozitif yönlü bir etkisine rastlanmamıştır (Gürültü, 2016; Gür vd., 2018; Teyfur, 2017; Demir ve Kutlu, 2017). Ayrıca sosyal medya kullanım amaçları değişkeninin akademik erteleme davranışı değişkeni üzerinde doğrudan pozitif bir etkiye sahip olduğu anlaşılmıştır.

Ardından sosyal medya kullanım amaçları değişkeninin modelde aracı etkiye sahip olup olmadığı incelenmiş ve aracı etkisi tespit edilmiştir. Buna göre öğrencilerin sosyal medya bağımlılık düzeyleri, akademik erteleme davranışları üzerinde doğrudan pozitif etki yaratmaz iken sosyal medya kullanım amaçlarına bağlı olarak akademik erteleme davranışları üzerinde etkiye sahip olabilmektedir. Araştırmanın bu sonuca ulaşmasını sağlayan nedenlerden biri olarak sosyal medya bağımlılı̆̆ı değişkeninin faktör yüklerine göre analize dahil edilen indikatörleri ile sosyal medya kullanım amaçları değişkeninin indikatörlerinin uyum sağlaması gösterilebilir. Verilerden öğrencilerin sosyal medya bağımlılı̆̆ının bilgiye ulaşma ve güncel kalma kaynaklı oluştuğu, kullanım amaçlarında da bilgiye erişim, güncel kalma eğilimlerinin yanı sıra boş zaman değerlendirme, iletişim aracı olarak kullanma eğilimlerinin de bulunduğu görülebilmektedir.

İlerleyen zamanlarda yapilabilecek olan çalışmalarda modele farklı değişkenler eklenebilir, değişkenlerde moderatör ilişki araştırılabilir, örneklem büyüklüğü artırılabilir, hedeflenen anakütle farklı eğitim düzeylerinde seçilebilir veya kullanılan ölçekler değiştirilebilir. 


\section{KAYNAKÇA}

Acun, İ., Yücel, C., Belenkuyu, C. \& Keleş, S. (2017). Üniversite Öğrencilerinin Sosyal Medya Kullanım Amaçlarının İncelenmesi. Kuram ve Uygulamada Ĕ̆itim Yönetimi, 23(4), 559-602.

Aitken, M. E. (1982). A personality profile of the college student procrastinator (Unpublished Doctoral Dissertation). University of Pittsburgh.

Akın, M. (2017). A Research on the Impacts of the Young People's Internet Addiction Levels and their Social Media Preferences. International Review of Management and Marketing, 7(2), 256-262.

Akıncı Vural, Z. B. \& Bat, M. (2010). Yeni bir iletişim ortamı olarak sosyal medya: Ege Üniversitesi İletişim Fakültesine yönelik bir araştırma. Journal of Yasar University, 20 (5), 3348-3382.

Ayeni, P. T. (2019). Social Media Addiction: Symptoms And Way Forward. The American Journal of Interdisciplinary Innovations and Research, 1(4), 19-42.

Balkıs, M. (2006). Öğretmen Adaylarının Davranışlarındaki Erteleme Eğiliminin, Düşünme ve Karar Verme Tarzları ile İlişkisi. Doktora Tezi, Dokuz Eylül Üniversitesi: İzmir.

Balkıs, M., Duru, E., Buluş, M. \& Duru, S. (2006). Üniversite Öğrencilerinde Akademik Erteleme Eğiliminin Çeşitli Değişkenler Açısından İncelenmesi. Ege Eğitim Dergisi, 7 (2), 57-73.

Baron, R. M. \& Kenny, D. A. (1986). The Moderator-Mediator Variable Distinction in Social Psychological Research: Conceptual, Strategic, and Statistical Considerations. Journal of Personallity and Social Psychology, 51(6), 1173-1182.

Çömlekçi, M. F. \& Başol, O. (2019). Gençlerin Sosyal Medya Kullanım Amaçları ile Sosyal Medya Bağımlılı̆̆ı İlişkisinin İncelenmesi. Manisa Celal Bayar Üniversitesi Sosyal Bilimler Dergisi, 17(4), 173-188.

Demir, Y. \& Kutlu, M. (2017). İnternet bağımlılı̆̆ı, akademik erteleme ve akademik başarı arasındaki ilişkiler. The Journal of Academic Social Science Studies, 61, 91-105.

Doğan, D. (2019). SmartPLS ile Veri Analizi. Ankara: Zet Yayınları.

Durdu, A. (2019). Ortaokul 7. ve 8. Sinıf Öğrencilerinin Sosyal Medya Bağımlılıkları ve Akademik Erteleme Davranışlarının İncelenmesi. Yüksek Lisans Tezi, Toros Üniversitesi: Mersin.

Filiz, O., Erol, O., Dönmez, F. İ. \& Kurt, A. A. (2014). BÖTE Bölümü Öğrencilerinin Sosyal Ağ Siteleri Kullanım Amaçları ile İnternet Bağımlılıkları Arasındaki İlişkinin İncelenmesi. Journal of Instructional Technologies \& Teacher Education, 3(2), 17-28.

Gür, S., Bakırcı, Ö., Karabaş, B., Bayoğlu, F. \& Atli, A. (2018). Üniversite Öğrencilerinin Sosyal Medya Bağımlılı̆̆ının Akademik Erteleme Davranışları Üzerindeki Etkisi. İnönü Üniversitesi Eğitim Bilimleri Enstitüsü Dergisi, 5(10), 68-77. 
Gürbüz, S. (2019). AMOS ile Yapısal Eşitlik Modellemesi Temel İlkeler ve Uygulamalı Analizler. Ankara: Seçkin Yayıncılık.

Gürültü, E. (2016). Lise Öğrencilerinin Sosyal Medya Bağımlılıkları ve Akademik Erteleme Davranışları Arasındaki İlişkinin İncelenmesi. Yüksek Lisans Tezi, Marmara Üniversitesi: İstanbul.

Hair, J., Hult, G., Ringle, C. \& Sarstedt, M. (2014). A Primer on Partial Least Squares Structural Equation Modeling (PLS-SEM). Los Angeles: Sage.

Hair, J., Hult., Ringle, C. \& Sarstedt, M. (2017). A Primer on Partial Least Squares Structural Equation Modeling (PLS-SEM) Second Edition. Los Angeles: Sage.

Hazar, M. (2011). Sosyal Medya Bağımlılığı-Bir Alan Çalışması. İletişim Kuram ve Araştırma Dergisi, 32, 151-176.

Hootsuite \& We Are Social (2020). Digital 2020 Global Digital Overview. Erişim Tarihi: 10.03.2020, https://datareportal.com/reports/digital-2020-global-digital-overview

Idubor, I. (2015). Investigating Social Media Usage and Addiction Level among Undergraduates in University of Ibadan, Nigeria. British Journal of Education, Society \& Behavioural Science,7(4), 291-301.

Kızılkaplan, A. (2018). Sosyal medya bağımlılık türleri. 2. Marmara Lisansüstü İletişim Öğrencileri Kongresi, İstanbul: Marmara Üniversitesi.

Klassen, R. M. \& Kuzucu, E. (2009). Academic procrastination and motivation of adolescents in Turkey. Educational Psychology, 29(1), 69-81.

McCay-Peet, L. \& Quan-Haase, A. (2017). What is social media as a concept and what questions can social media research help us to answer? Sloan, L. \& Quan-Haase, A. (Ed.) Handbook of Social Media Research Methods (s. 13-26) içinde. London, UK: Sage.

Papacharissi, Z. (2015). We have always been social. Social Media + Society, 1(1): 1-2.

Savcı, M. \& Aysan, F. (2017). Teknolojik Bağımlılıklar ve Sosyal Bağlılık: İnternet Bağımlılığı, Sosyal Medya Bağımlılığı, Dijital oyun bağımlılı̆̆ı ve Akıllı telefon Bağımlılığının Sosyal Bağlılığı Yordalayıcı Etkisi. Düşünen Adam Dergisi, 30, 202-216.

Solmaz, B., Tekin, G., Herzem, Z., \& Demir, M. (2013). İnternet ve sosyal medya kullanımı üzerine bir uygulama. Selçuk Üniversitesi İletişim Fakültesi Akademik Dergisi, 7(4), 23-32.

Solomon, L. J. \& Rothblum, E. D. (1984). Academic Procrastination: Frequency and Cognitive Behavioral Correlates. Journal of Counseling Psychlogy, 31(4), 503-509.

Surveysystem. (2016). Sample size calculator [Örneklem büyüklügü hesaplama aracı]. Erişim tarihi: 16.03.2020, Erişim: https://www.surveysystem.com/sscalc.htm

Şahin, C. \& Yağcı, M. (2017). Sosyal Medya Bağımlılığı Ölçeği - Yetişkin Formu: Geçerlilik ve Güvenirlik Çalışması. Ahi Evran Üniversitesi Kırşehir Eğitim Fakültesi Dergisi (KEFAD) 18(1),523-538. 
Şimşek Kandemir, A. (2019). Yapısal Eşitlik Modeli Boş Zaman Aktivitesinin Yaşam Tatmini Üzerine Etkisi. Gazi Kitabevi: Ankara.

Taşçı, B. \& Ekiz, S. (2018). Serbest zaman aktivitesi olarak sosyal medya bağımlılığı. 2. Uluslararası İletişimde Yeni Yönelimler Konferansı: Eğlence ve Ürün Yerleştirme, İstanbul: İstanbul Ticaret Üniversitesi. TBM - Uygulayıcı (Erişim Tarihi: 11.03.2020). Erişim adresi: https://uygulayici.tbm.org.tr/

Teyfur, M., Akpunar, B., Safali, S., \& Ercengiz, M. (2017). Eğitim fakültesi öğrencilerin akademik erteleme davranışları ile sosyal medya bağımlılığı arasındaki ilişkinin farklı değişkenler açısından incelenmesi. Turkish Studies International Periodical for the Languages, Literature and History of Turkish or Turkic, 12 (33), 625-640.

Tutgun Ünal, A. (2015). Sosyal Medya Bağımlılı̆̆ı Üniversite Öğrencileri Üzerine Bir Araştırma. Doktora Tezi, İstanbul: Marmara Üniversitesi.

TÜiK (2018). Hanehalkı Bilişim Teknolojileri (BT) Kullanım Araştırması, 2018. Haber Bülteni, Erişim: 09.03.2020. http:/ / www.tuik.gov.tr/PreHaberBultenleri.do?id=27819

TÜIK (2019). Hanehalkı Bilişim Teknolojileri (BT) Kullanım Araştırması, 2019. Haber Bülteni, Erişim: 09.03.2020. http://www.tuik.gov.tr/PreHaberBultenleri.do?id=30574

Yurdakoş, K. \& Biçer, E. B. (2019). İnternet Bağımlılık Düzeyinin Akademik Ertelemeye Etkisi: Sağlık Yönetimi Öğrencileri Üzerine Bir Araştırma. YYÜ Eğitim Fakültesi Dergisi, 16(1), 243-278.

Zhao, X., Lynch, J. G. \& Chen, Q. (2010). Reconsidering Baron and Kenny: Myths and Truths about Mediation Analysis. Journal of Consumer Research Inc., 37(2), 197-206. 